\title{
The Entrepreneurial State: debunking public vs. private sector miths
}

Mariana Mazzucato

Anthem Press

ISBN 978-0-857282-52-1

Janaina Oliveira Pamplona da Costa*

Sandro Mendonça**

André Sica de Campos ${ }^{* * *}$

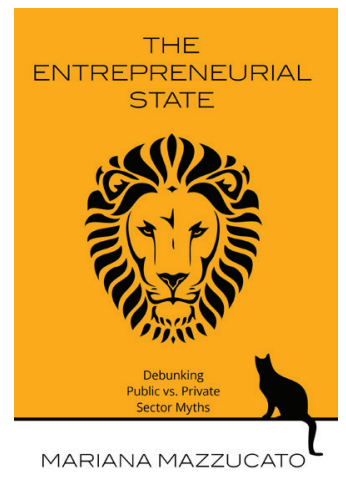

Na contemporaniedade o consenso dominante ainda é de um Estado visto como o parente pobre da "modernidade econômica". Nessa perspectiva, o Estado deve sair da frente (desregulamentar), diminuir (privatizar-se) e deixar seguir (liberalizar). Esse é o consenso que ainda prevalece no Banco Central Europeu, chefiado pelo ex-banqueiro que cuida dos mercados financeiros, e no Reino Unido no governo liderado pelo ex-publicitário David Cameron do Partido Conservador, por meio de políticas de austeridade em relação ao gasto público. Estas, portanto, são as prescrições de política para a recuperação do crescimento econômico pós-crise de 2008: mais finança privada, menos Estado social. O livro The entrepreneurial State: debunking public vs. private sector myths, da professora Mariana Mazzucato, do SPRU - University of Sussex, contrapõe-se a esta visão e argumenta que o Estado tem papel estratégico na economia, devendo assumir o comando sobre atividades não realizadas por outros agentes econômicos (ampliando a intervenção anticíclica keynesiana), tarefa que requer uma capacidade visionária por parte do Estado, associada a uma intencionalidade de implementação de estratégias, bem como de

\footnotetext{
* Universidade Estadual de Campinas (Unicamp), Campinas (SP), Brasil. Email: jpamplona@ige.unicamp.br

** Instituto Universitário de Lisboa (ISCTE), Lisboa, Portugal. Email: sfm@iscte.pt

*** Universidade Estadual de Campinas (Unicamp), Limeira (SP), Brasil. Email: andre.campos@fca.unicamp.br
} 
habilidades burocrático-administrativas (no sentido weberiano) e de conhecimento específico sobre tecnologias e setores.

\section{A inovação, esse motor da economia}

A premissa-base da obra é que a inovação importa. Na inovação, o Estado deve não somente corrigir falhas de mercado (por exemplo, por meio do financiamento para pesquisa básica e projetos de infraestrutura), mas também abrir espaço para o investimento privado dinamizando-o, cabendo ao Estado sinalizar para a sociedade sua visão, definir sua missão e formular e executar um planejamento coerente. Segundo a autora, é sobretudo nos países emergentes na nova fase da globalização (tais como China, Coreia do Sul e mesmo o Brasil) que a ideia de um Estado útil a uma economia real dinâmica tem mais expressão.

O centro de gravidade deste livro não está, assim, alinhado com o saber-vulgar dos economistas-convencionais. De acordo com a autora, o Estado tem sido e pode ser um poderoso e efetivo agente criativo, sendo que não reconhecer isso será uma incompetência empírica, uma cegueira teórica e um erro político profundo. Para apoiar esta tese, Mazzucato mobiliza uma forte bagagem prática e de evidência atual e histórica, bem como uma abrangente compreensão analítica da lógica da mudança econômica.

\section{Estado, esse empreendedor}

Em primeiro lugar, Mariana Mazzucato nos lembra que o Estado moderno tem sido um ator verdadeiramente estratégico na criação dos novos setores dinâmicos, lucrativos e criadores de emprego de alto valor agregado, e não apenas um agente que dá incentivos às empresas e cria as condições facilitadoras para que os personagens econômicos privados invistam em fatores de melhoramento competitivo. Contrariamente ao que diz a retórica dominante, a autora persuade-nos que a verdade dos fatos é que o Estado tem ficado na "linha da frente". O Estado tem sido o dínamo que assume os primeiros riscos nas tecnologias portadoras de futuro (isto é, lidera e está na vanguarda das novas escolhas). Ou seja, mais do que ser o apoio de último recurso de economias de mercado que muitas vezes entram em crise pela acumulação de decisões insustentáveis dos agentes privados, o Estado tem sido historicamente o "empreendedor de primeira instância", diríamos nós aqui, de economias que se desenvolvem no longo prazo pelo desenvolvimento estrutural e incorporação de progresso nas atividades geradoras de valor econômico e social. 


\section{Estado, essa força dinâmica}

Segundo Mazzucato, a visão convencional que advoga um papel de Estado mínimo no processo de inovação assenta-se em uma série de mitos que são por ela questionados, tais como:

- contrariamente ao senso comum, o investimento em P\&D na empresa não assegura necessariamente inovação e crescimento, sendo relevantes as condiçôes específicas desta;

- refuta o argumento em favor da importância exacerbada de pequenas empresas para a geração de emprego e crescimento econômico, a qual não está assegurada a priori, uma vez que dados sobre seu papel na economia são inconclusivos;

- contesta o entendimento de que o venture capital pode financiar novos setores intensivos em tecnologia, pois evidências apontam que este tende a se concentrar em tecnologias com grande potencial de crescimento e investe em atividades de baixas complexidade tecnológica e intensidade de capital, em vez de fomentar tecnologias disruptivas de maior risco ao longo do ciclo inovativo;

- refuta o argumento de que patentes espelham a intensificação do uso do conhecimento para a inovação, uma vez que um número crescente de patentes é de baixo valor, pouco intensivo em conhecimento científico e não resulta em inovações;

- contesta a visão de que o problema principal dos países europeus reside em suas dificuldades na comercialização do conhecimento., Segundo a autora, o dilema europeu baseia-se em um sistema científico mais fraco, quando comparado ao norte-americano, e em firmas menos inovativas;

- refuta a ideia de que investimentos privados exigem principalmente um processo de desburocratização, argumentando que não é suficiente subsidiar pesadamente a Pesquisa e Desenvolvimento (P\&D) privada, pois o ambiente de negócios é mais importante do que medidas de políticas isoladas.

\section{Marés tecnológicas, essa realidade}

A autora sustenta seus argumentos a favor do Estado empreendedor com base em estudos de caso que analisam a inter-relação de tecnologias-chave, investimento e atuação estatal, desempenho do setor privado por meio de pequenas e grandes empresas e do sistema de financiamento privado. Os casos do desenvolvimento do 
algoritmo que levou ao sucesso do Google, financiado com recursos da National Science Foundation (NSF) norte-americana, das moléculas que deram origem à biotecnologia e foram descobertas em laboratórios do Medical Research Council do Reino Unido, assim como do surgimento da Internet e da computação por meio de investimentos do Departamento de Defesa (DoD) norte-americano (via projetos financiados e coordenados pela Defense Advanced Research Projects Agency-DARPA), são alguns dos exemplos discutidos pela autora para demonstrar que o papel do Estado vai além de estímulo à demanda ou de escolha de setores vencedores (pickingwinners). Nestes casos, os Estados norte-americano e britânico desempenharam papel objetivo, proativo e empreendedor, resultando na diminuição dos riscos inerentes à inovação, e foram capazes de criar um sistema de atores em rede, alavancando as virtudes do setor privado em benefício nacional nos horizontes de médio e longo prazos. O Estado deve, assim, mobilizar recursos que possam permitir e assegurar que o conhecimento e a inovação se difundam entre os setores-chave da economia.

\section{Os (novos) casos clássicos}

Esta visão sobre o papel do Estado está, portanto, em colisão frontal com o entendimento comum que foi se enraizando ao longo dos últimos 30 anos. Porém, é surpreendente ver como tecnologias-chave são tributárias de iniciativas e financiamentos públicos. A Apple, em particular o iPhone, é para Mazzucato uma verdadeira experimentum crucis. Nenhum componente-chave de um smart-phone surgiu independentemente de investimento e estratégias públicas, tais como: microprocessador (financiado pela DARPA); telas multitoque (financiadas pelo DoD norte-americano); Global Positioning System (GPS) (financiado pelo DoD e pela Marinha de Guerra norte-americanos); e tela de cristal líquido (financiada pelo DoD, pela NSF e pelo National Institute of Health norte-americanos). Sem estes insumos, Steve Jobs, segundo a autora um grande designer e integrador de sistemas, não teria lançado mais do que um interessante mas inconsequente artigo de consumo, um brinquedo sem importância.

\section{Os grandes desafios globais do nosso tempo}

A autora constrói estes argumentos para defender que o Estado, mais uma vez, deve liderar o processo atual de investimento para a Revolução Industrial Verde, com base em tecnologias ambientalmente sustentáveis. Como no passado, tais tecnologias 
requerem alto investimento, são intensivas em conhecimento e de alto risco. Alguns países já se adiantaram no investimento em tecnologias ambientalmente sustentáveis, tais como a China, a Alemanha e a Dinamarca; e dada a forte característica de dependência da trajetória histórica da tecnologia (path-dependence), aqueles que fizerem o primeiro investimento devem se beneficiar por seu pioneirismo. Para Mazzucato, é importante criar um arcabouço de financiamento que permita ao Estado recuperar parte dos recursos públicos investidos. Segundo a autora, não caberia ao Google devolver para a NSF parte dos lucros obtidos com o algoritmo que o estabeleceu? E, ainda mais, faz-se necessário que neste arcabouço do problema criado pela financialização da economia, em que os investimentos iniciais em conhecimento fundamental são públicos, os riscos e perdas são socializados enquanto as recompensas são privatizadas, ocorra uma parceria público-privada verdadeiramente produtiviva (e não especulativa), que viabilize a distribuição dos benefícios a todos os envolvidos, inclusive o Estado empreendedor. Mazzucato argumenta que recuperar o investimento público por meio do sistema tributário é incompleto, pois a liberdade no planejamento do pagamento de impostos pelos agentes privados é muito ampla no contexto de globalização e liberalização atual. Por esse motivo, atores como bancos nacionais de investimento, no caso da China o China Development Bank, no da Alemanha o German Development Bank (KfW) e no do Brasil o Banco Nacional de Desenvolvimento Econômico e Social (BNDES), devem ocupar papel central no investimento para a Revolução Industrial Verde, pois permitem ao Estado empreendedor recuperar diretamente (e não indiretamente pela tributação) os investimentos de alto risco em P\&D e inovação. 
A Revista Brasileira de Inovação está aberta à comunidade científica para divulgação de artigos originais e inéditos, de natureza teórica ou aplicada, resultados de pesquisas, bem como trabalhos que contribuam para o resgate da história das instituições brasileiras no campo da ciência, da tecnologia e da inovação.

São aceitas submissões de artigos com no máximo 8.000 palavras e resenhas de até 1.000 palavras, inéditos em português, inglês ou espanhol.

Todos os trabalhos devem ser submetidos via Sistema Eletrônico de Editoração de Revistas (SEER) e se enquadrar na linha editorial da revista, observando as normas e orientações indicadas a seguir:

- os trabalhos devem ser redigidos conforme a norma de apresentação de artigos da Associação Brasileira de Normas Técnicas - ABNT (NBR6022) ou norma ISO equivalente, digitados no editor de texto Word 6.0 (extensão doc. ou docx.), texto na fonte Times New Roman 12; configuração de página A4; margens direita, superior e inferior com 2,5cm; margem esquerda com 3cm; espaçamento entrelinhas de 1,5; recuo de 1,25 na primeira linha; alinhamento do texto justificado; e numeração de páginas no canto superior direito;

- $\quad$ os artigos devem ser submetidos contendo resumo, título e palavras-chave em seu idioma original e em inglês e classificação segundo o Classification System for Journal Articles do Journal Economic Literature. O resumo/abstract deve ter no máximo 150 palavras e possuir de três a cinco palavras-chave;

- as resenhas devem versar sobre livros publicados nos últimos três anos, relacionados à inovação e que estejam alinhados ao escopo editorial da revista;

- as obras citadas no corpo do texto e em notas de rodapé (autor, ano da publicação e, quando for o caso, página) deverão estar completas nas referências bibliográficas ao final do texto.

Os artigos são avaliados no sistema blind review por três pareceristas de instituições distintas daquela à qual o(s) autor(es) está(ão) vinculado(s) e as resenhas são avaliadas pelos editores da revista.

Os direitos autorais dos trabalhos aprovados são automaticamente transferidos à $R B I$ como condição para sua publicação, podendo ser compartilhados desde que com o reconhecimento de sua autoria e publicação inicial nesta revista.

Mais informações: <http://www.ige.unicamp.br/ojs/rbi/> 